\title{
Multivariate analysis of biliary flow-related factors and post-Kasai survival in biliary atresia patients
}

\author{
Alexandre Rodrigues FERREIRA, Thaís Costa Nascentes QUEIR0Z, Paula Vieira Teixeira VIDIGAL, \\ Raquel di Paula FERREIRA, David Campos WANDERLEY and Eleonora Druve Tavares FAGUNDES
}

\begin{abstract}
Background - Biliary atresia represents the most common surgically treatable cause of cholestasis in newborns. If not corrected, secondary biliary cirrhosis invariably results. Objective - To evaluate, through multivariate analysis, the prognostic factors associated with the presence of biliary flow and survival with the native liver following Kasai portoenterostomy. Methods - The study analyzed data from 117 biliary atresia patients who underwent portoenterostomy and had suitable histological material for evaluation. A logistic regression model was used to assess the presence of biliary flow. Survival was investigated through Kaplan-Meier curves and Cox-adjusted models. Results - One third of patients achieved biliary flow and the median age at surgery was 81 days. Age at surgery, albumin, postoperative complications, biliary atresia structural malformation (BASM), liver architecture, larger duct diameter at porta hepatis, and cirrhosis (Ishak score) were the initial variables for the multivariate analysis. Age at surgery $>90$ days was the only variable associated with the absence of biliary drainage. Survival analysis revealed that the absence of biliary flow $(P<0.0001)$, age at surgery $>90$ days $(P=0.035)$, and the presence of BASM $(P<0.0001)$, alone, could predict death or need for liver transplantation. Multivariate analysis demonstrated that the absence of biliary flow $(P<0.0001$ hazard ratio [HR] 6.25, 95\% confidence interval [CI] 3.19-12.22) and the presence of BASM ( $P=0.014$ HR 2.16, 95\% CI 1.17-3.99) were associated with lowest survival with the native liver. Conclusion - Age at surgery $>90$ days was associated with absence of biliary flow. The presence of biliary drainage and the absence of structural malformations are cornerstone features for higher survival rates with the native liver.
\end{abstract}

HEADINGS - Biliary atresia. Cholestasis. Newborn infant. Prognosis. Liver transplantation. Hepatic portoenterostomy.

\section{INTRODUCTION}

Biliary atresia (BA) is characterized by inflammation and progressive fibrosis of the biliary tract, resulting in flow obstruction, persistent cholestasis, and secondary cirrhosis ${ }^{(1)}$. It is a disease of unknown etiology with an incidence of 1:3.125 to 1:18.000 live births ${ }^{(2,3)}$. BA is the most common cause of obstructive jaundice in the first three months of life ${ }^{(4)}$ and most frequent indication for pediatric liver transplantation ${ }^{(5)}$.

Serum bilirubin levels in the postoperative period are excellent predictors of long-term native liver survival (NLS). A good prognosis is expected with levels $<1 \mathrm{mg} / \mathrm{dL}$, three months after a Kasai procedure and is associated with lower transplantation rates. While liver cirrhosis develops progressively in jaundiced patients, in anicteric patients secondary biliary cirrhosis evolves slowly ${ }^{(6)}$. Approximately $10 \%-20 \%$ of patients with BA have congenital malformations including thoracic and abdominal heterotaxy, polysplenia or asplenia, intestinal malrotation, and preduodenal portal vein ${ }^{(7)}$. The presence of malformations has been associated with poor surgical outcomes ${ }^{(7,8)}$.

Several studies have investigated the association between liver histological findings and clinical outcomes, but with discordant results. Some describing outcomes associated with the progression of fibrosis ${ }^{(9-11)}$, whereas others determining that only ductular proliferation $^{(12)}$, giant cell transformation ${ }^{(13)}$ or ductal remnants
$<150 \mu \mathrm{m}^{(14)}$ were associated with a worse evolution. Conversely, some studies have not found any correlation between liver histological findings and a successful portoenterostomy ${ }^{(15,16)}$.

This study attempted to identify prognostic factors associated with the presence of biliary flow after Kasai portoenterostomy using multivariate analysis, and secondly to analyze factors related to higher NLS rates in patients with BA.

\section{METHODS}

\section{Patients and study design}

Patients diagnosed with BA from the Hospital das Clinicas Minas Gerais Federal University (HC-UFMG) were enrolled; the study was retrospective from 1979-2008 and prospective between 2009 and May 2016. The cohort was not a probability sample, but was consisted of patients referred to the Pediatric Hepatology Department of the HC-UFMG diagnosed with BA and subjected to the Kasai procedure, and who had surgical biopsy material appropriate for histological analysis.

\section{Variables and definitions}

The following clinical variables were studied: sex, age at surgery, presence of BA structural malformation (BASM), use of corticosteroids after hepatoportoenterostomy, early postoperative complications, and episodes of cholangitis. 
BASM refers to the presence of one or more of the following findings: polysplenia, abnormal abdominal situs, intestinal malrotation, abdominal vascular abnormality, or congenital heart disease. The steroid therapy used was a five-day methylprednisolone or prednisolone regímen $(10,5,2.5,1.25,0.75 \mathrm{mg} / \mathrm{Kg} /$ day or $4,2,1$, $0.5,0.25 \mathrm{mg} / \mathrm{Kg} /$ day). Early postoperative complications occur up to the seventh postoperative day and may be clinical and/or surgical. Clinical causes include: infection, acute renal failure, seizure, ascites, upper digestive hemorrhage, and liver failure, among others. Surgical causes were intestinal obstruction, sinus, and dehiscence. The diagnosis of post-Kasai cholangitis, up to six months after the procedure, was based on criteria used by Lien et al. ${ }^{(17)}$ : unexplained fever (body temperature $>38^{\circ} \mathrm{C}$ ), acholic feces, increased jaundice, or positive hemoculture.

\section{Laboratory variables}

Albumin $(>3.5,2.8-3.5,<2.8 \mathrm{~g} / \mathrm{dL})$, coagulogram (prothrombin activity [AP]: $\geq 70 \%$ and $<70 \%$ ), hepatic enzymes (aspartate aminotransferase [AST] and alanine aminotransferase [ALT]), and canalicular enzyme (gamma-glutamyltransferase [GGT]) levels, dosage of bilirubin levels (total bilirubin [TB] and direct bilirubin [DB]) on admission and on the sixth postoperative month.

\section{Histopathological variables}

Histopathological analysis of liver biopsy slides was carried out by two pathologists from the Pathological Anatomy Service of the HC-UFMG, blinded to patient data and date of examination. Liver fragments were fixed and processed according to routine histological techniques until paraffin embedding. Five sections with a thickness of 5.0-7.0 $\mu \mathrm{m}$ were stained with hematoxylin and eosin (HE), Gomori or Masson's trichrome, Picrosirius red (PSR) and periodic acid-Schiff (PAS) both with and without diastase treatment.

The degree of fibrosis, the presence or absence of cirrhosis and the inflammatory activity were assessed by Metavir ${ }^{(18)}$ and Ishak ${ }^{(19)}$ scores. Giant cell transformation and biliary plugs were categorized as absent or present. The lobular hepatic architecture was classified as preserved, partially subverted, or subverted.

In the porta hepatis, the ductal remnants were measured in micrometers and the largest measurement was obtained by calculating the average between the greater diameter and its opposite length in a straight angle. This measurement was studied as continuous and dichotomized variables as $<150$ or $\geq 150$ micrometers $^{(20)}$. The largest diameter of the ductal remnants of the porta hepatis was measured separately by each investigator, using the same model of Leica microscope and lenses. Needle and wedge biopsies were adequate when at least ten portal tracts were identified.

The variables studied were associated with the presence or absence of biliary flow, which was defined as a serum bilirubin $<2$ $\mathrm{mg} / \mathrm{dL}$, six months after the surgery ${ }^{(21)}$.

\section{Statistical analysis}

Statistical analysis was performed using the Statistical Package for Social Sciences, version 20 (IBM, Armonk, New York, USA) and MedCalc, version 16.8.4 (MedCalc Software bvba, Ostend, Belgium). Quantitative data were described by average and standard deviations when a normal distribution was verified by the Shapiro-Wilk test or median values (Q1/Q3) in the absence of a normal distribution. Qualitative variables were described by absolute frequencies and percentages. Non-normal distributions were compared between two independent groups using the MannWhitney test, the Student's $t$-test was used to compare averages with a normal distribution, while the asymptotic Pearson's chi-square test was used to compare categorical variables.

Receiver operator characteristic (ROC) ${ }^{(22)}$ curves were built using age at surgery and the larger duct diameter of porta hepatis against the biliary flow. The area under the ROC (AUROC) curve determined the degree of discrimination: 1 perfect, $0.90-0.99$ excellent, $0.80-0.89$ very good, $0.70-0.79$ good, $0.60-0.69$ moderate, and $<0.6$ poor $^{(23)}$. The discriminatory cut-off point was determined as the best relationship between sensitivity and specificity.

Reliability analysis was carried out using Cohen's kappa coefficient for categorical variables and Bland-Altman plot analysis, and the intraclass correlation coefficient (ICC) was used for quantitative variables. Cohen's Kappa coefficient determined the extent of agreement between observers for the histological analysis of surgical biopsies. In this regard, the Landis and Koch $^{(24)}$ score was used: $<0$ poor, $0-0.19$ negligible, $0.2-0.39$ low, $0.4-0.59$ moderate, $0.6-0.79$ high, or $0.8-1.0$ almost perfect. The ICC correlation was stratified as follows ${ }^{(25)}:<0.4$ poor, $\geq 0.4$ and $<0.75$ satisfying, or $\geq 0.75$ excellent. Results with $P<0.05$ were considered statistically significant.

Analysis of the association between the study variables and the presence of biliary flow was performed using the logistic regression model. First, univariate analysis was used to describe isolated relationships of intervening variables and the presence of biliary flow. Variables with $P<0.20$ and less than $20 \%$ of missing data were candidates for multivariate logistic regression. Multivariate models were adjusted in each stage by removing the variable with the highest $P$-value until a final model was reached in which all variables were statistically significant $(P<0.05)$. The adjustment quality of the logistic regression was verified by the Hosmer and Lemeshow test. Survival analysis was carried out using Kaplan-Meier curves and the Cox-adjusted model. NLS was analyzed and the Log-rank or Wilcoxon curves were compared.

\section{Ethical aspects}

The Research Ethics Committee of the UFMG approved the study (protocol number 77.0.203000-09).

\section{RESULTS}

\section{Data analysis}

Between 1979-2016, 172 patients were subjected to Kasai portoenterostomy at the HC-UFMG. Of these, 55 (32\%) were excluded because their biopsies were not available or the material was not suitable for review. Ultimately, 117 patients, 62 $(53 \%)$ females and $55(47 \%)$ males were identified. The median age at surgery was 81 days $(\mathrm{Q} 1 / \mathrm{Q} 3=64.5 / 105)$, wherein $71 / 117$ $(60.7 \%)$ patients underwent surgery when aged $<90$ days old and $39(33.3 \%)$ had biliary flow. The AUROC curve regarding age at surgery and biliary flow was $0.658(95 \%$ CI $0.559-0.757), P=0.005$. The cut-off point for age at surgery was 90 days (sensitivity [48.7\%] and specificity [74.4\%]).

Of the 117 patients, BASM was observed in $14(12 \%)$ infants and $62(53 \%)$ received steroid therapy after hepatoportoenterostomy. Early postoperative complications were observed in $71(60.7 \%)$ patients and the most common were infection (38.5\%) and ascites (19.7\%), surgical complications occurred in $17(14.5 \%)$ patients and $71 \%$ had at least one episode of cholangitis. 
Surgical liver biopsies revealed a median of 15 portal tracts $(\mathrm{Q} 1 / \mathrm{Q} 3=9 / 19)$ and the histological analysis revealed that $17.1 \%$ and $13.7 \%$ of patients were cirrhotic according to the Metavir and Ishak scores, respectively. Biliary plugs and giant cell transformation occurred in $87(74.4 \%)$ and $53(45.3 \%)$ biopsies, respectively. The AUROC curve regarding the caliber of the largest ductal remnant of porta hepatis and biliary flow was $0.426(95 \%$ CI $0.317-0.535)$, $P=0.193$, indicating poor discrimination. The cut-off point for the caliber was $150 \mu \mathrm{m}$ (sensitivity [48.7\%] and specificity [74.4\%]). Only $46(39.3 \%)$ patients from the original sample had a ductal remnant measuring $\geq 150 \mu \mathrm{m}$. Descriptive analysis of laboratory and histological data are shown in TABLE 1.

\section{Concordance of histological analysis of categorical and quantitative descriptive variables among investigators}

Results of the comparisons of descriptive categorical variables of the biopsies overlapped between the two investigators for lobular architecture (kappa $=0.867, P<0.001)$, giant cell transformation (kappa $=0.903, P<0.001)$, and fibrosis according to Metavir (kappa $=0.901, P<0.001)$. There was a high agreement for fibrosis according to the Ishak score (kappa $=0.786, P<0.001)$, inflammatory activity according to the Metavir score (kappa $=0.767, P$ $<0.001$ ), and biliary plugs (kappa $=0.763, P<0.001$ ). The correlation was low only for inflammatory activity according to the Ishak score (kappa $=0.322, P<0.001$ ).

Analysis of quantitative variables revealed a high correlation among investigators for the number of portal spaces (ICC 0.992 , 95\% CI $0.988-0.994, P<0.001)$ and the caliber of the largest ductal remnant of porta hepatis (ICC $0.998,95 \%$ CI 0.988-0.999, $\mathrm{P}<0.001)$. This agreement for quantitative variables was confirmed by the Bland-Altman plot.

\section{Univariate analysis to predict the absence of biliary flow}

Age at surgery $>90$ days was shown to be associated with a statistically significant absence of postoperative biliary flow $(P=0.035)$. Sex, laboratory findings on admission (TB and DB, aminotransferases, GGT, albumin and AP), postoperative complications, corticosteroid therapy, cholangitis, and BASM were the clinical and laboratory variables that were not found to be associated with biliary drainage (TABLE 2).

Analysis of histological variables revealed that liver architecture, caliber of the largest ductal remnant of the porta hepatis, fibrosis, and inflammatory activity according to both Metavir and Ishak scores, biliary plugs, and giant cell transformation were not associated with biliary flow (TABLE 3).

\section{Multivariate analysis to predict the absence of biliary flow}

Age at surgery, albumin, postoperative complications, BASM, liver architecture, diameter of the canaliculus, and cirrhosis according to the Ishak score were the initial variables for the multivariate analysis. Age at surgery older than 90 days $(P=0.035$, OR $2.49,95 \%$ CI 1.07-5.79) was isolated in the final logistic model as a predictor of absent biliary drainage.

\section{Survival}

NLS was $59.5 \%, 48.6 \%, 33.2 \%$, and $25 \%$ in $1,2,5$ and 10 years, respectively. Univariate analysis showed that the absence of biliary flow, age at surgery $>90$ days or the presence of BASM alone, could predict the need for liver transplantation or death (FIGURE 1).
TABLE 1. Descriptive analysis of laboratory and histological data of patients diagnosed with biliary atresia.

\begin{tabular}{|c|c|}
\hline Variables & $\mathrm{n}=117$ \\
\hline TB $(\mathrm{mg} / \mathrm{dL}) *$ median $(\mathrm{Q} 1 / \mathrm{Q} 3)$ & $10.1(8.1 / 12.2)$ \\
\hline $\mathrm{DB}(\mathrm{mg} / \mathrm{dL}) *$ mean $\pm \mathrm{DP}$ & $7.2 \pm 2.8$ \\
\hline $\operatorname{AST}(\mathrm{U} / \mathrm{L}) * *$ median $(\mathrm{Q} 1 / \mathrm{Q} 3)$ & $220(134 / 346.8)$ \\
\hline $\operatorname{ALT}(\mathrm{U} / \mathrm{L}) * *$ median $(\mathrm{Q} 1 / \mathrm{Q} 3)$ & $149(87.8 / 233.3)$ \\
\hline GGT (U/L)** median (Q1/Q3) & $567.4(314 / 1013.5)$ \\
\hline Albumin $(\mathrm{g} / \mathrm{dL}) * * *$ mean $\pm \mathrm{DP}$ & $3.4 \pm 0.6$ \\
\hline$<2.8$ & $13(13.8 \%)$ \\
\hline 2.8 to 3.5 & $42(44.7 \%)$ \\
\hline$>3.5$ & $39(41.5 \%)$ \\
\hline Prothrombin activity $* * * *-$ median $(\mathrm{Q} 1 / \mathrm{Q} 3)$ & $86(69 / 100)$ \\
\hline$<70 \%$ & $25(25.3 \%)$ \\
\hline$\geq 70 \%$ & $74(74.7 \%)$ \\
\hline TB 6th month of postoperative - median (Q1/Q3) & $5.8(1.1 / 11.4)$ \\
\hline DB 6th month postoperative - median (Q1/Q3) & $4.2(0.6 / 8)$ \\
\hline $\mathrm{N}$ space porta - median (Q1/Q3) & $15(9 / 19)$ \\
\hline \multicolumn{2}{|l|}{ Liver architecture } \\
\hline Preserved & $40(34.2 \%)$ \\
\hline Partially subverted & $49(41.9 \%)$ \\
\hline Subverted & $28(23.9 \%)$ \\
\hline \multicolumn{2}{|l|}{ Cirrhosis Metavir } \\
\hline Yes & $20(17.1 \%)$ \\
\hline No & $97(82.9 \%)$ \\
\hline \multicolumn{2}{|l|}{ Cirrhosis Ishak } \\
\hline Yes & $16(13.7 \%)$ \\
\hline No & $101(86.3 \%)$ \\
\hline \multicolumn{2}{|l|}{ Inflammatory Activity Metavir } \\
\hline Absent or light (A0-1) & $102(87.2 \%)$ \\
\hline Moderate or acentuada (A2-3) & $15(12.8 \%)$ \\
\hline \multicolumn{2}{|l|}{ Inflammatory activity Ishak } \\
\hline Absent or light (Sum $=0-3$ ) & $107(91.5 \%)$ \\
\hline Moderate (Sum = 4-6) & $10(8.5 \%)$ \\
\hline \multicolumn{2}{|l|}{ Biliary plugs } \\
\hline Absent & $30(25.6 \%)$ \\
\hline Present & $87(74.4 \%)$ \\
\hline \multicolumn{2}{|l|}{ Giant cell transformation } \\
\hline Absent & $64(54.7 \%)$ \\
\hline Present & $53(45.3 \%)$ \\
\hline $\begin{array}{l}\text { Caliber of the larger ductal remnant - median } \\
\text { (Q1/Q3) }\end{array}$ & $125(80 / 210)$ \\
\hline$\geq 150 \mu \mathrm{m}$ & $46(39.3 \%)$ \\
\hline$<150 \mu \mathrm{m}$ & $71(60.7 \%)$ \\
\hline
\end{tabular}

* 116 patients evaluated (missing data $0.09 \%$ ). **115 patients evaluated (missing data 1.7\%). ***94 patients evaluated (missing data 19.7\%). **** 99 patients evaluated (missing data $15.4 \%)$. 
TABLE 2. Univariate analysis of clinical and laboratory variables to predict the absence of biliary flow.

\begin{tabular}{|c|c|c|c|c|c|}
\hline \multirow{2}{*}{ Variables } & \multicolumn{2}{|c|}{ TB 6th postoperative month } & \multirow{2}{*}{ OR } & \multirow{2}{*}{$95 \% \mathrm{CI}$} & \multirow{2}{*}{$P$} \\
\hline & $<2 \mathrm{mg} / \mathrm{dL}(\mathrm{n}=39)$ & $\geq 2 \mathrm{mg} / \mathrm{dL}(\mathrm{n}=78)$ & & & \\
\hline \multicolumn{6}{|l|}{ Sex } \\
\hline Male & $19(34.5 \%)$ & $36(65.5 \%)$ & 1 & & \\
\hline Female & $20(32.3 \%)$ & $42(67.7 \%)$ & 1.11 & $0.51-2.39$ & 0.793 \\
\hline$>90$ days & $10(21.7 \%)$ & $36(78.3 \%)$ & 2.49 & $1.07-5.79$ & 0.035 \\
\hline \multicolumn{6}{|l|}{ Age at surgery } \\
\hline$<60$ days & $9(45 \%)$ & $11(55 \%)$ & 1 & & \\
\hline $60-90$ days & $20(39.2 \%)$ & $31(60.8 \%)$ & 1.27 & $0.45-3.61$ & 0.656 \\
\hline $\mathrm{DB}$ admission $(\mathrm{mg} / \mathrm{dL})-$ mean $\pm \mathrm{DP}$ & $7.32 \pm 2.3$ & $7.18 \pm 2.98$ & 0.98 & $0.85-1.13$ & 0.798 \\
\hline AST (U/L) - median (Q1/Q3) & $220(160.5 / 496)$ & $213(133 / 332.5)$ & 0.99 & $0.99-1.00$ & 0.263 \\
\hline ALT (U/L) - median (Q1/Q3) & $145(84.5 / 232)$ & $152(87.5 / 235.5)$ & 0.99 & $0.99-1.00$ & 0.349 \\
\hline GGT (U/L) - median (Q1/Q3) & $518.8(285 / 997)$ & $574.5(337 / 1051.7)$ & 1.00 & $0.99-1.00$ & 0.863 \\
\hline \multicolumn{6}{|l|}{$\operatorname{Albumin}(\mathrm{g} / \mathrm{dL}) *$} \\
\hline Mean $\pm \mathrm{DP}$ & $3.51 \pm 0.53$ & $3.31 \pm 0.59$ & 0.51 & 2.86 & 0.096 \\
\hline$>3.5$ & $18(46.2 \%)$ & $21(53.8 \%)$ & 1 & $0.24-1.12$ & \\
\hline 2.8 to 3.5 & $14(33.3 \%)$ & $28(66.7 \%)$ & 1.71 & $0.70-4.21$ & 0.240 \\
\hline \multicolumn{6}{|l|}{ PO* complications } \\
\hline No & $19(41.3 \%)$ & $27(58.7 \%)$ & 1 & & \\
\hline Yes & $20(28.2 \%)$ & $51(71.8 \%)$ & 1.79 & $0.82-3.92$ & 0.143 \\
\hline \multicolumn{6}{|l|}{ Use of corticosteroids } \\
\hline No & $19(34.5 \%)$ & $36(65.5 \%)$ & 1 & & \\
\hline Yes & $20(32.3 \%)$ & $42(67.7 \%)$ & 1.11 & $0.51-2.39$ & 0.793 \\
\hline \multicolumn{6}{|l|}{ Cholangitis** } \\
\hline No & $13(43.3 \%)$ & $17(56.7 \%)$ & 1 & & \\
\hline Yes & $25(33.8 \%)$ & $49(66.2 \%)$ & 1.50 & $0.63-3.57$ & 0.361 \\
\hline \multicolumn{6}{|l|}{ BASM* } \\
\hline Absent & $38(36.9 \%)$ & $65(63.1 \%)$ & 1 & & \\
\hline Present & $1(7.1 \%)$ & $13(92.9 \%)$ & 7.60 & $0.96-60.41$ & 0.055 \\
\hline
\end{tabular}

* Variables of the multivariate analysis. ** 104 patients evaluated (missing data 11.1\%). PO: postoperative. 
TABLE 3. Univariate analysis of histological variables to predict the absence of biliary flow.

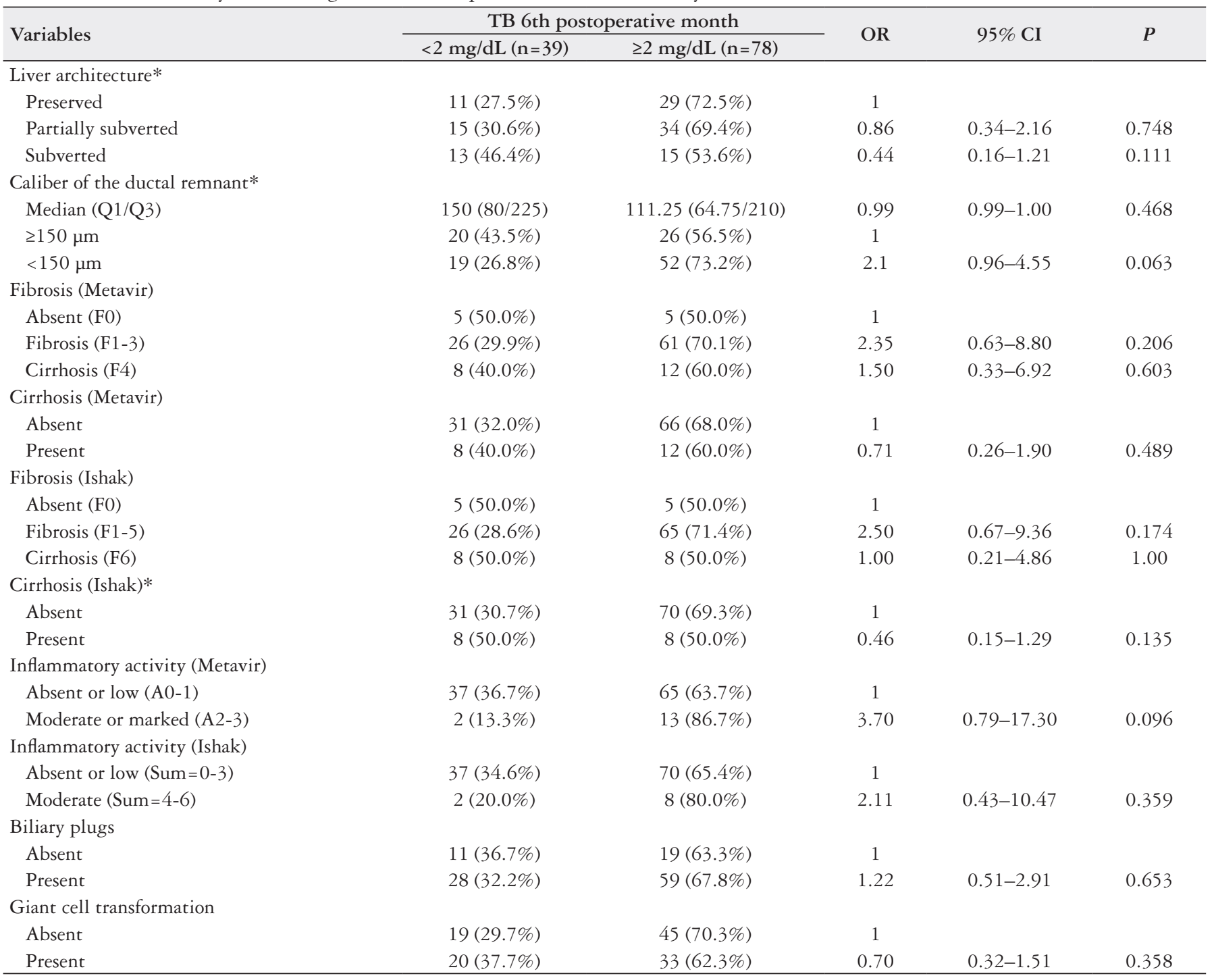

* Variables in multivariate analysis.

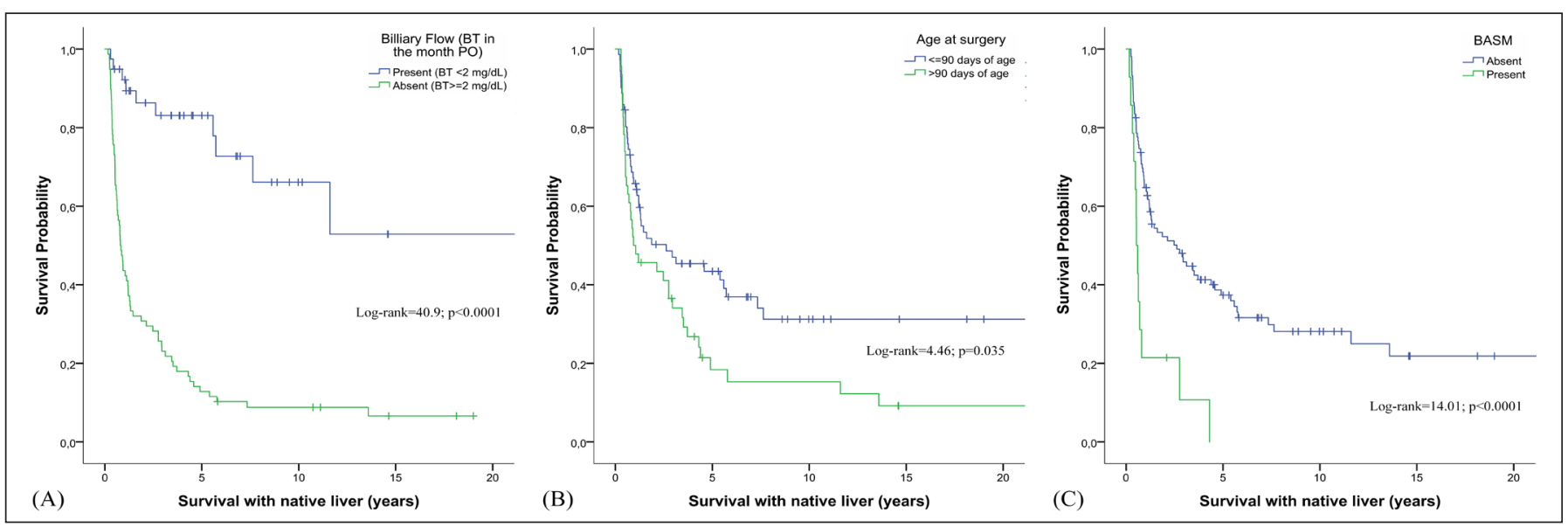

FIGURE 1. Kaplan-Meier curves of survival with native liver after Kasai procedure. (A) Biliary flow. (B) Age at surgery. (C) BASM probability of survival/survival (years). TB: total bilirubin, PO: postoperative; BASM: biliary atresia structural malformation. 
The variables selected for multivariate analysis were biliary flow $(P<0.0001)$, age at surgery $>90$ days $(P=0.035)$, BASM $(P<0.0001)$, and postoperative complications $(P=0.179)$. After step-by-step logistic regression, lack of biliary drainage $(P<0.0001$ HR $6.25,95 \%$ CI 3.19-12.22) and presence of BASM $(P=0.014$ HR $2.16,95 \%$ CI 1.17-3.99) were independently associated with the lowest NLS.

\section{DISCUSSION}

The patient's age at the moment of the Kasai procedure is a main predictor of the effectiveness of the procedure ${ }^{(8)}$. A Japanese study with 242 patients subjected to the Kasai procedure demonstrated an inverse correlation between age at surgery and the rate of jaundice improvement. All patients who had surgery $<30$ days of age achieved a jaundice-free status. Meanwhile, only $7.7 \%$ of patients achieved biliary drainage when subjected to surgery between 121-150 days of life ${ }^{(26)}$. Biliary drainage and a high percentage of anicteric patients may result even when surgery is undertaken after 60 days of age, with excellent results until 80 days and worsening outcomes for surgery in infants aged $>100$ days ${ }^{(27)}$. A study of 735 patients after Kasai hepatoportoenterostomy, alleged that the biliary flow is not closely related to age at surgery when the procedure is carried out at $<90$ days of age, but there is a decrease in biliary flow in children operated after this age ${ }^{(28)}$. Herein, age at surgery $<90$ days was the only independent variable associated with the presence of biliary drainage. Nevertheless, when comparing patients operated at $<60$ days of age to those between $60-90$ days, no statistically significant difference was observed regarding biliary flow $(P=0.656)$. These findings may reflect the heterogeneity and the multifactorial nature of BA, in which the deleterious effect of age at surgery becomes more obvious after a certain time threshold, for example 90 days.

Only one-third of patients achieved biliary drainage, a rate that is lower than that described in France ${ }^{(8)}(38 \%)$, the Netherlands ${ }^{(29)}$ $(36 \%)$, the $\mathrm{USA}^{(7)}(45.6 \%)$, and $\operatorname{Japan}^{(28)}(57 \%)$. In our sample, the lower percentage of patients who achieved biliary flow may be explained by the higher-than-average median age at surgery of 81 days. Studies from other countries differ regarding this variable: 54 days in the United Kingdom ${ }^{(30)}, 57$ in France ${ }^{(31)}, 68$ in Switzerland ${ }^{(32)}$ and 61 days in the USA ${ }^{(33)}$. Reasons for this discrepancy include misdiagnosis by the primary care pediatrician, who oftentimes manages an infant with cholestasis as physiologic or breast-milk jaundice and delays the patient's referral to a tertiary center or a propaedeutic evaluation delay due to institutional policies, especially in the first years of our working group.

To explain the different surgical outcomes associated with the achievement of biliary flow, several studies have investigated the relationship between the lumen diameter of the remaining bile ducts of the porta hepatis and the outcome after portoenterostomy. A better biliary drainage and clinical course was observed in patients with a ductal lumen $\geq 150 \mu \mathrm{m}$ and in those with multiple or single ductal structures measuring $<150 \mu \mathrm{m}$ when compared to those who did not have the same ductal structure ${ }^{(20)}$. A good biliary flow in the postoperative period and a sharp decrease in the levels of serum bilirubin was reported in patients with BA with ductal structures of $300-500 \mu \mathrm{m}$ in diameter, whereas the biliary flow was scarce and jaundice was persistent among those with a ductal lumen of $<150 \mu \mathrm{m}^{(34)}$. Conversely, but in accordance with this study, other authors have not observed any correlation between the caliber of bile ducts in the porta hepatis and the success of portoenterostomy in establishing biliary drainage ${ }^{(35,36)}$. Different cut-off points for the size of the ductal remnant, technical difficulties associated with its measurement, and the emphasis in the larger diameter of one single duct rather than the average of all observable ducts, could explain these contradictory results and constitute a limitation in the reported studies.

Reports of NLS rates are highly inconsistent and vary in the short term (1-3 years) between 20.3\%-75.8\%. Long-term results were similarly variable, ranging from $24 \%-52.8 \%$ in 10 years ${ }^{(37)}$. Herein, the NLS rates were found to be within these values. Biliary drainage and age at surgery are the most commonly studied variables to explain these results.

Our study shows that biliary drainage was an independent factor for higher NLS rates. Schneider et al. concluded that patients with $\mathrm{TB}<2 \mathrm{mg} / \mathrm{dL}$ in the third month after the Kasai procedure had a 2 -year NLS of $86 \%$, whereas those with TB $>2 \mathrm{mg} / \mathrm{dL}$ had a 2 -year NLS of only $20 \%{ }^{(38)}$ which are very similar to those found in the present cohort. Thus, a dosage of TB $<2 \mathrm{mg} / \mathrm{dL}$ between the third and sixth month of the postoperative period may be a good predictor of better results after portoenterostomy. Furthermore, the presence of biliary flow after the Kasai procedure has been described as an important variable associated with $\operatorname{NLS}^{(7,29,39)}$.

Extrahepatic malformations have been historically described in BA and have been commonly correlated with poor prognosis ${ }^{(8)}$. The risk of death or need for liver transplantation increases 1.9 times in patients with BA splenic malformations ${ }^{(7)}$. In this cohort, the presence of BASM was associated with a lower NLS. This finding should be a warning to the hepatologist about the prognosis after the Kasai procedure.

Previous reports have described a correlation between age at surgery and survival. An evaluation of 743 patients, showed that the 5-year NLS was $58.1 \%$ in those undergoing surgical procedures at $<30$ days of age and $27 \%$ in those subjected to surgery aged $>90$ days $^{(40)}$. However, the outcome after Kasai portoenterostomy may only be partially dependent on age because despite fibrosis and cirrhosis are inevitable if the disease is not treated. The association between these histological findings and the patient's age is neither linear nor predictable and, thus, several uncertainties remain regarding the exact moment of the onset of the disease. Therefore, these reports support surgery even for patients who are $>100$ days of age ${ }^{(30,41)}$. Herein, age at surgery $>90$ days was associated with a lower NLS only in univariate analysis. A potential explanation may be the importance of age at surgery to establish biliary drainage, which is ultimately a fundamental variable for a higher NLS.

Many histopathological variables have been evaluated in the attempt to predict survival. The intensity of liver fibrosis, a main indicator of disease progression, is the most analyzed histological parameter ${ }^{(16)}$. Fibrosis was classified according its severity into three types (mild, moderate, or severe) and showed a correlation between the intensity of the fibrosis and NLS. Infants with severe fibrosis had worse overall survival $(18 \%$ at 2 years and $0 \%$ at 10 years) when compared to those with mild and moderate fibrosis $(42 \% \text { at } 2 \text { years and } 10 \text { years })^{(10)}$. However, other studies in accordance with our study have not found a similar association ${ }^{(7,39)}$. Controversial outcomes may be explained by different techniques and scoring systems used to quantify fibrosis. Additionally, there are inherent difficulties in the analysis of the extent of the fibrosis, the histological sample and the staining methods used ${ }^{(42)}$. 
This study analyzed potential factors that could influence biliary drainage and survival. Few studies have considered this evaluation using multivariate analysis and, in most, the variable considered was survival and not biliary drainage. Nevertheless, the retrospective nature and the size of cohort of our study, justified by the scarcity of the disease and the exclusion criteria (about a third of patients were excluded), were limiting factors. Another limitation was the use of the single largest ductal remnant measurement instead of the average of all ductal remnants present in the porta hepatis. Technical difficulties in obtaining the latter measurement made us opt for the former method. Nevertheless, the strong agreement between investigators may indicate an appropriate choice of method.

\section{CONCLUSION}

We conclude that age at surgery $>90$ days was an independent risk factor for the absence of biliary flow. Furthermore, the presence of biliary drainage and the absence of structural malformations are important factors for a higher NLS. Altering disease evolu- tion of infants with malformations in impossible; however, the possibility of becoming anicteric may increase by an early Kasai portoenterostomy.

\section{Authors' contribution}

Ferreira AR: designed the research, wrote the manuscript, reviewed the manuscript. Queiroz TCN: performed the research, wrote the manuscript, reviewed the manuscript. Vidigal PVT: histopathological analysis of hepatic biopsies, reviewed the manuscript. Ferreira RP: performed the research, reviewed the manuscript. Wanderley DC: histopathological analysis of hepatic biopsies, reviewed the manuscript. Fagundes EDT: designed the research, reviewed the manuscript.

\section{Orcid}

Alexandre Rodrigues Ferreira. Orcid: 0000-0001-6749-8980.

Thaís Costa Nascentes Queiroz. Orcid: 0000-0001-9917-9749.

Paula Vieira Teixeira Vidigal. Orcid: 0000-0002-7003-5159.

Raquel di Paula Ferreira. Orcid: 0000-0003-3128-140X.

David Campos Wanderley. Orcid: 0000-0003-1201-9449.

Eleonora Druve Tavares Fagundes. Orcid: 0000-0002-5671-9570.

Ferreira AR, Queiroz TCN, Vidigal PVT, Ferreira RP, Wanderley DC, Fagundes EDT. Análise multivariada de variáveis relacionadas ao fluxo biliar e sobrevida pós-Kasai em pacientes com atresia biliar. Arq Gastroenterol. 2019;56(1):71-8.

RESUMO - Contexto - A atresia biliar representa a principal causa de colestase tratada cirurgicamente durante o período neonatal. Se a criança não for operada, ela evolui invariavelmente para cirrose biliar secundária. Objetivo - Avaliar, através de análise multivariada, os fatores prognósticos associados à presença de fluxo biliar e à sobrevida com fígado nativo após a realização da portoenterostomia de Kasai. Métodos - O estudo analisou 117 pacientes com atresia biliar submetidos à portoenterostomia e com material histológico adequado para avaliação. O modelo de regressão logística foi utilizado para avaliar a presença de fluxo biliar. Sobrevida foi estudada através das curvas Kaplan-Meier e ajuste do modelo de Cox. Resultados - Um terço dos pacientes obteve fluxo biliar e a mediana de idade à cirurgia foi de 81 dias. Idade à cirurgia, albumina, complicação pós-operatória, BASM (do inglês, biliary atresia structural malformation), arquitetura hepática, diâmetro do maior canalículo no porta hepatis e cirrose, segundo o escore de Ishak, foram as variáveis iniciais da análise multivariada. Idade à cirurgia maior que 90 dias de vida foi a única variável associada à ausência de drenagem biliar. A análise de sobrevida mostrou que as variáveis: ausência de fluxo biliar $(P<0,0001)$, idade à cirurgia maior que 90 dias $(P=0,035)$ e presença de BASM $(P<0,0001)$, isoladamente, predizem morte ou necessidade de transplante hepático. Na análise multivariada, ausência de fluxo biliar ( $P<0,0001$ HR:6,25 [IC95\% 3,19; 12,22]) e presença de BASM ( $P=0,014$ HR:2,16 [IC95\% 1,17; 3,99]) mostraram-se associadas, com significância estatística, a menor sobrevida com fígado nativo. Conclusão - Idade à cirurgia maior que 90 dias foi identificada como fator de risco independente para ausência de fluxo biliar. Além disso, a presença de drenagem biliar e a ausência de malformações estruturais da atresia biliar são variáveis fundamentais para a maior sobrevida com fígado nativo.

DESCRITORES - Atresia biliar. Colestase. Recém-nascido. Prognóstico. Transplante de fígado. Portoenterostomia hepática.

\section{REFERENCES}

1. Petersen C. Pathogenesis and treatment opportunities for biliary atresia. Clin Liver Dis. 2006;10:73-88.

2. Sokol RJ, Mack CL, Narkewicz MR, Karrer FM. Pathogenesis and outcome of biliary atresia: current concepts. J Pediatr Gastroenterol Nutr. 2003;3:4-21.

3. Chardot C. Biliary atresia. Orphanet J Rare Dis. 2006;1:28.

4. Fawaz R, Baumann U, Ekong U, Fischler B, Hadžić N, Mack CL, et al. Guideline for the Evaluation of Cholestatic Jaundice in Infants: Joint Recommendations of the North American Society for Pediatric Gastroenterology, Hepatology, and Nutrition and European Society for Pediatric Gastroenterology, Hepatology, and Nutrition. J Pediatr Gastroenterol Nutr. 2016;64:154-68.

5. Feldman AG, Mack CL. Biliary Atresia. J Pediatr Gastroenterol Nutr. 2015;61:167-75.

6. Ohhama Y, Shinkai M, Fujita S, Nishi T, Yamamoto H. Early prediction of longterm survival and the timing of liver transplantation after the Kasai operation. J Pediatr Surg. 2000;35:1031-4

7. Superina RA, Magee JC, Brandt ML, Healey PJ, Tiao G, Ryckman FC, et al. The anatomic pattern of biliary atresia identified at time of Kasai hepatoportoenterostomy and early postoperative clearance of jaundice are significant predictors of transplant-free survival. Ann Surg. 2011;254:577-85.
8. Chardot C, Buet C, Serinet M, Golmard JL, Lachaux A, Roquelaure B et al. Improving outcomes of biliary atresia: French national series 1986-2009. J Hepatol. 2013;58:1209-17.

9. Russo PA, Magee JC, Anders RA, Bove KE, Chung C, Cummings OW, et al. Key Histopathologic Features of Liver Biopsies That Distinguish Biliary Atresia From Other Causes of Infantile Cholestasis and Their Correlation With Outcome. Am J Surg Pathol. 2016;40:1601-15.

10. Weerasooriya VS, White F V, Shepherd RW. Hepatic fibrosis and survival in biliary atresia. J Pediatr. 2004;144:123-5.

11. Muthukanagarajan SJ, Karnan I, Srinivasan P, Sadagopan P, Manickam S. Diagnostic and Prognostic Significance of Various Histopathological Features in Extrahepatic Biliary Atresia. J Clin Diagnostic Res. 2016;10:EC23-7.

12. Santos JL, Kieling CO, Meurer L, Vieira S, Ferreira CT, Lorentz A et al. The extent of biliary proliferation in liver biopsies from patients with biliary atresia at portoenterostomy is associated with the postoperative prognosis. J Pediatr Surg. 2009;44:695-701.

13. Azarow KS, Phillips MJ, Sandler AD, Hagerstrand I, Superina RA. Biliary atresia: Should all patients undergo a portoenterostomy? J Pediatr Surg. 1997;32: 168-72. 
14. Altman RP, Lilly JR, Greenfeld J, Weinberg A, van Leeuwen K, Flanigan L. A multivariable risk factor analysis of the portoenterostomy (Kasai) procedure for biliary atresia: twenty-five years of experience from two centers. Ann Surg. 1997;226:348-55.

15. Lampela H, Kosola S, Hikkilä P, Lohi J, Jalanko H, Pakarinen MP. Native Liver Histology After Successful Portoenterostomy in Biliary Atresia. J Clin Gastroenterol. 2014;48:721-8.

16. Czubkowski P, Cielecka-Kuszyk J, Rurarz M, Kamińska D, Markiewicz-Kijewska M, Pawłowska J. The limited prognostic value of liver histology in children with biliary atresia. Ann Hepatol. 2015;14:902-9.

17. Lien T, Bu L, Wu J, Chen HL, Chen AC, Lay M, et al. Use of Lactobacillus casei rhamnosus to prevent cholangitis in Biliary Atresia after Kasai Operation A randomized study. J Pediatr Gastroenterol Nutr. 2014;60:654-8.

18. Bedossa P, Poynard T. An algorithm for the grading of activity in chronic hepatitis C. Hepatology. 1996;24:289-93.

19. Ishak K, Baptista A, Bianchi L, Callea F, De Groote J, Gudat F, et al. Histological grading and staging of chronic hepatitis. J Hepatol. 1995;22:696-9.

20. Chandra RS, Altman RP. Ductal remnants in extrahepatic biliary atresia: A histopathologic study with clinical correlation. J Pediatr. 1978;93:196-200.

21. Vejchapipat P, Passakonnirin R, Sookpotarom P, Chittmittrapap S, Poovorawan Y. High-dose steroids do not improve early outcome in biliary atresia. J Pediatr Surg. 2007;42:2102-5

22. Hanley JA, McNeil BJ. A method of comparing the areas under receiver operating characteristic curves derived from the same cases. Radiology. 1983;148:839-43.

23. Afessa B, Gajic O, Keegan MT. Severity of Illness and Organ Failure Assessment in Adult Intensive Care Units. Crit Care Clin. 2007;23:639-58.

24. Landis JR, Koch GG. The Measurement of Observer Agreement for Categorical Data. Biometrics. 1977;33:159-74.

25. Fleiss JL, Levin B, Paik MC. Statistical methods for rates and proportions. 3rd ed. Wiley-Interscience: New York, 2003.

26. Nio M, Wada M, Sasaki H, Tanaka H. Effects of age at Kasai portoenterostomy on the surgical outcome: a review of the literature. Surg Today. 2015;45: 813-8.

27. Wong KKY, Chung PHY, Chan IHY, Lan LCL, Tam PKH. Performing Kasai portoenterostomy beyond 60 days of life is not necessarily associated with a worse outcome. J Pediatr Gastroenterol Nutr. 2010;51:631-4.

28. Nio M, Ohi R, Miyano T, Saeki M, Shiraki K, Tanaka K, et al. Five- and 10-yea survival rates after surgery for biliary atresia: a report from the Japanese Biliary Atresia Registry. J Pediatr Surg. 2003;38:997-1000.
29. de Vries W, de Langen ZJ, Groen H, Scheenstra R, Peeters PMJG, Hulscher JBF, et al. Biliary atresia in the Netherlands: Outcome of patients diagnosed between 1987 and 2008. J Pediatr 2012;160:638-44.e2.

30. Davenport M, De Ville De Goyet J, Stringer MD, Mieli-Vergani G, Kelly DA McClean P, et al. Seamless management of biliary atresia in England and Wales (1999-2002). Lancet. 2004;363:1354-7.

31. Serinet M-O, Broué P, Jacquemin E, Lachaux A, Sarles J, Gottrand F, et al Management of patients with biliary atresia in France: results of a decentralized policy 1986-2002. Hepatology. 2006;44:75-84.

32. Wildhaber BE, Majno P, Mayr J, Zachariou Z, Hohlfeld J, Schwoebel M, et al Biliary atresia: Swiss national study, 1994-2004. J Pediatr Gastroenterol Nutr. 2008;46:299-307.

33. Shneider BL, Brown MB, Haber BA, Whitington PF, Schwarz KB, Squires RH, et al. A multicenter study of the outcome of biliary atresia in the United States, 1997 to 2000. J Pediatr. 2006;148:467-74.

34. Ohi R, Chiba T, Endo N. Morphologic studies of the liver and bile ducts in biliary atresia. Acta Paediatr Jpn. 1987;29:584-9.

35. Baruah RR, Bhatnagar V, Agarwala S, Gupta SD. Correlation of pre- and post-operative liver function, duct diameter at porta hepatis, and portal fibrosis with surgical outcomes in biliary atresia. J Indian Assoc Pediatr Surg. 2015;20:184-8.

36. Langenburg SE, Poulik J, Goretsky M, Klein AA, Klein MD. Bile duct size does not predict success of portoenterostomy for biliary atresia. J Pediatr Surg. 2000;35:1006-7.

37. Jimenez-Rivera C, Jolin-Dahel KS, Fortinsky KJ, Gozdyra P, Benchimol EI International incidence and outcomes of biliary atresia. J Pediatr Gastroenterol Nutr. 2013;56:344-54.

38. Shneider BL, Magee JC, Karpen SJ, Rand EB, Narkewicz MR, Bass LM, et al Total Serum Bilirubin within 3 Months of Hepatoportoenterostomy Predicts Short-Term Outcomes in Biliary Atresia. J Pediatr. 2016;170:211-7.

39. Nightingale S, Stormon MO, O'Loughlin E V, Shun A, Thomas G, Benchimol EI, et al. Early Post-Hepatoportoenterostomy Predictors of Native Liver Survival in Biliary Atresia. J Pediatr Gastroenterol Nutr. 2016;64:203-9.

40. Serinet M-O, Wildhaber BE, Broué P, Lachaux A, Sarles J, Jacquemin E, et al. Impact of age at Kasai operation on its results in late childhood and adolescence: a rational basis for biliary atresia screening. Pediatrics. 2009;123:1280-6.

41. Davenport M, Puricelli V, Farrant P, Hadžić N, Mieli-Vergani G, Portmann B, et al. The outcome of the older ( $>$ or $=100$ days) infant with biliary atresia. J Pediatr Surg. 2004;39:575-81.

42. Standish RA. An appraisal of the histopathological assessment of liver fibrosis Gut. 2006;55:569-78. 